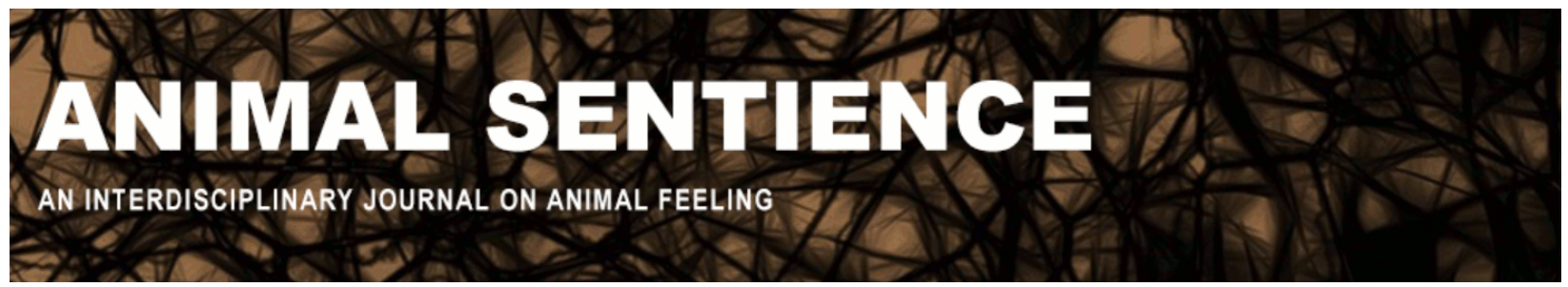

Balcombe, Jonathan (2017) Fishes are gaining academic respect. Animal Sentience 8(7)

DOI: $10.51291 / 2377-7478.1265$

Date of submission: 2017-11-26

Date of acceptance: 2017-12-20

(c)

This article has appeared in the journal Animal

Sentience, a peer-reviewed journal on animal

cognition and feeling. It has been made open access,

free for all, by WellBeing International and deposited

in the WBI Studies Repository. For more information,

please contact

wbisr-info@wellbeingintl.org.

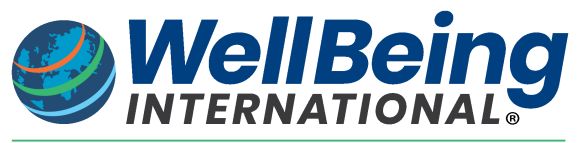

SOLUTIONS FOR PEOPLE, ANIMALS AND ENVIRONMENT 


\title{
Fishes are gaining academic respect
}

Response to Commentary on Balcombe on Fish Knows

\author{
Jonathan Balcombe \\ Independent Scientist and Author
}

\begin{abstract}
I respond to five commentaries on my 2016 book What a Fish Knows. The commentaries express more harmony than dissent about my interpretation of fishes as cognitive, aware individuals deserving better treatment by humankind.
\end{abstract}

Jonathan Balcombe is an ethologist and author of several books on animals' capacity to think, feel and experience pleasure. His most recent book, What a Fish Knows, explores the remarkable lives of the planet's most misunderstood and maligned vertebrates. Balcombe lectures widely, and currently teaches a course in animal sentience for the Viridis Graduate Institute. www.jonathan-balcombe.com

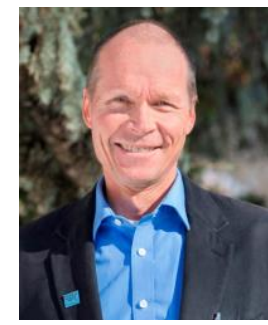

\section{Introduction}

At the outset, I thank all those who have written commentaries on my book (Balcombe 2016a; 2016b). I hope that discourse of this nature helps move us towards a greater understanding and appreciation of our underwater cousins. In the brief response that follows, I address each commentator's contributions in the order they appear in the journal.

\section{Response to Commentaries}

Wintner, as is apparent from his commentary, is a staunch and faithful defender of fishes and their habitats. He was advocating for them decades before I took up their mantle. Through his many books - written in his inimitable voice and graced by his own magnificent photographs, and his fierce campaigning for policy changes, especially in his home state of Hawaii where a rampant, state-facilitated aquarium trade has decimated reef fish populations - Wintner has done arguably more than anyone to sensitize the public to the beauty, diversity, and personalities of fishes.

Both in our advocacy for a sorely maligned and routinely underestimated taxon, and in our dissent with scholars who seek to keep fishes in their place, Wintner and I are closely aligned. He notes the failure of a reductionist, corticocentric approach (Key 2016; cf. Woodruff 2017) to account for emergent properties (consciousness and sentience) and for observed behaviors such as interspecies referential communication and collaboration (Bshary et al. 2006, Vail et al. 2013), and Machiavellian social dynamics in the cleaner-client fish mutualism (Bshary 2006). 
In also appealing to the individuality of fishes, Wintner bolsters a point I seek to advance by favoring the plural "fishes" over the usual generic plural "fish," which semantically homogenizes the individual members of a fabulous collection of over 33,000 species as if they were all one and the same object. Whereas "fishes" is a legitimate term, it is usually intended to refer to different species, not individuals. That fishes are individuals is axiomatic to biological variation. So, just as we refer to a group of "mammals and birds" not "mammal and bird," I favor the word "fishes" to the anonymizing word "fish."

Kramer offers a different sort of rebuke to our culture's impoverished view of fishes, by way of the electroreceptive communication system of the social South American glass knifefish (Eigenmannia virescens). A "jamming avoidance response" (JAR), in which individuals change their electric pulse frequency in response to another's closely matched signal, was once thought to be a purely instinctual behavior devoid of volition on the part of the fish. But careful studies by Kramer and others reveal JAR-related behaviors that bear the hallmarks of voluntary control. For example, large males sometimes forego electric organ discharges (EODs) in favor of physical attacks on real or simulated rivals, and subdominant fishes will increase their EOD frequencies to communicate submission (Hagedorn \& Heiligenberg 1985). These advances parallel our understanding of echolocation in bats. When I was studying bat communication in the 1980s, the structure (but curiously not the call rate) of a bat's echolocation was still regarded as being inflexible. Subsequently, bats have been found capable of modifying their call frequencies to suit different foraging situations, such as habitat, and/or the presence of other bats (e.g., Obrist 1995, Chiu et al. 2009).

Kramer notes several other behaviors befitting Eigenmannia as conscious individuals: their ability to track the unique and varying EOD frequencies and waveforms of shoal-mates, their long-term memory, their personalities, and their awareness of their own spatial position and social rank relative to group members. With well over a hundred species, each with unique EOD waveform characteristics, other facets of their communication system no doubt remain to be discovered.

Stauffer, taxonomist and ichthyologist, is on the whole favorable to my book, but he takes issue with some of my assertions, and finds me in places "a tad too anthropomorphic." He suggests that I err in placing birds and reptiles in separate classes of vertebrates. I acknowledge that there is a growing trend to lump them together; nevertheless, prevailing convention (e.g., Ripple et al. 2017; Allen et al. 2017) places them in separate classes. Stauffer believes I go too far in concluding that fishes' brains are doing the same as what ours do when they (and we) perceive a Kanizsa triangle, but I (Balcombe 2016b) am referring specifically to "completing an incomplete picture" and not necessarily to the cognitive processing by which this integration is achieved (p. 37), nor the conscious mental or emotional experience of it (though I would not rule that out, either).

Stauffer is right to question my statement that fishes probably invented hearing, and I would have done better to qualify it as being among vertebrates. I'm sure it is true, as he implies, that prevailing scientific opinion in the 1930s was not that fishes were deaf, but rather that scientific "proof" for their ability to hear was still lacking. 
I also agree that we should be careful about returning wild animals to the wild when we have taken them into captive environments. I hope that such concern will translate into seeking ways to avoid taking wild creatures captive in the first place. Some of the best fish studies I have seen were done wholly in the wild, and others with captive reared (i.e., not wild-caught) fishes.

Stauffer believes I am trying to "humanize" fishes, when in fact I am seeking to inject some more humanity into humans. Our treatment of fishes - indeed, our general treatment of practically all sentient animals - is, in a word, appalling. Some sixty billion terrestrial animals are not only killed by us, but a high proportion of them are confined to miserable conditions before we slaughter them. Add to that at least several hundred billion fishes hauled up in nets, hooked, gaffed, or trawled from the ocean floor, and a large volume tossed dead or dying back into the sea as bycatch, and it is plain to see that we humans have a long way to go before we can hold ourselves up as exemplars of a compassionate ethic.

Siebeck is more comfortable than Stauffer with my attribution of mammal-like consciousness to fishes; she takes no issue with my synthesis of the current state of fish cognition and behavior. Rather, in providing a more detailed account of her and her colleagues' research on human face recognition by archerfishes, she gives an excellent example of the flexibility and fidelity of a fish's mind. That this is achieved without mammalian brain anatomy supports the growing recognition, widely observable in nature, that evolution finds various ways of meeting challenges, be they anatomical, physiological, or cognitive. Evidence of human face recognition by a fish shows that cognitive abilities useful to an organism's own milieu can be extended to novel situations (Siebeck 2017). I thank Siebeck for pointing out that the question need not be "how can animals without a neocortex perform sophisticated cognitive feats?" but rather "why did the neocortex evolve at all?"

Lavenda, too, has no bone to pick with my assessment of fish capacities or the urgent need for a more sympathetic ethic in our relations with them. She provides a succinct recap of my book, touching on key elements and their implications for fish-human relations. She cites Mood's (2010) report, Worse Things Happen at Sea, as a powerful indictment of mankind's rapacious exploitation of fishes. Although I too cite this source in What a Fish Knows, I am nevertheless unconvinced by the methods used to come up with an estimate as high as 2.7 trillion fishes killed by humans each year (excluding such additional causes as bycatch, illegal fishing, and incidental mortality from lost or discarded fishing gear). Current recordkeeping in estimating the total body count is not very accurate, but I think a more conservative (though still grotesque) estimate of between several hundred billion (Cook \& Cowx 2004) and perhaps over a trillion is more reliable. Conversely, in citing Green's (2016) estimate of some two billion fishes caught each year by recreational anglers, Lavenda underestimates by more than 20 -fold the total of around fifty billion estimated by biologists Cook \& Cowx. Any way one estimates it, it's a monstrous number of fishes. 


\section{Conclusion}

These commentaries reflect growing academic support for fishes as cognitive, aware individuals deserving better treatment by humankind. It remains to be seen how our knowledge of the sophistication of fishes may translate into policy and practice, but I hope that the following little tale might be a harbinger of changes to come.

In April of this year (2017), I traveled to Europe for a 5-stop tour to speak about fishes and to promote What a Fish Knows. It became readily apparent that fish advocacy is growing in Europe. In Geneva, my well-attended speaking venue was decorated with professional banners and posters on the theme of fish protection. The next day, I joined local activists for a demonstration on the plight of fishes in a large downtown square adjoining the United Nations headquarters. Four thousand paper fishes were taped to the square to symbolize the magnitude of our exploitation of them. About 20 activists (and one very affable dog) crawled beneath a large fishing net where they lay for half an hour to protest the sorry plight of netted fishes. Others held banners and several people (myself included) spoke through a megaphone on the need for change in our policy and practices. It seemed fitting when, just as the demonstration ended, a gust of wind tore loose hundreds of paper fishes from their tenuous moorings, many of which floated over the perimeter fence to settle in the UN compound.

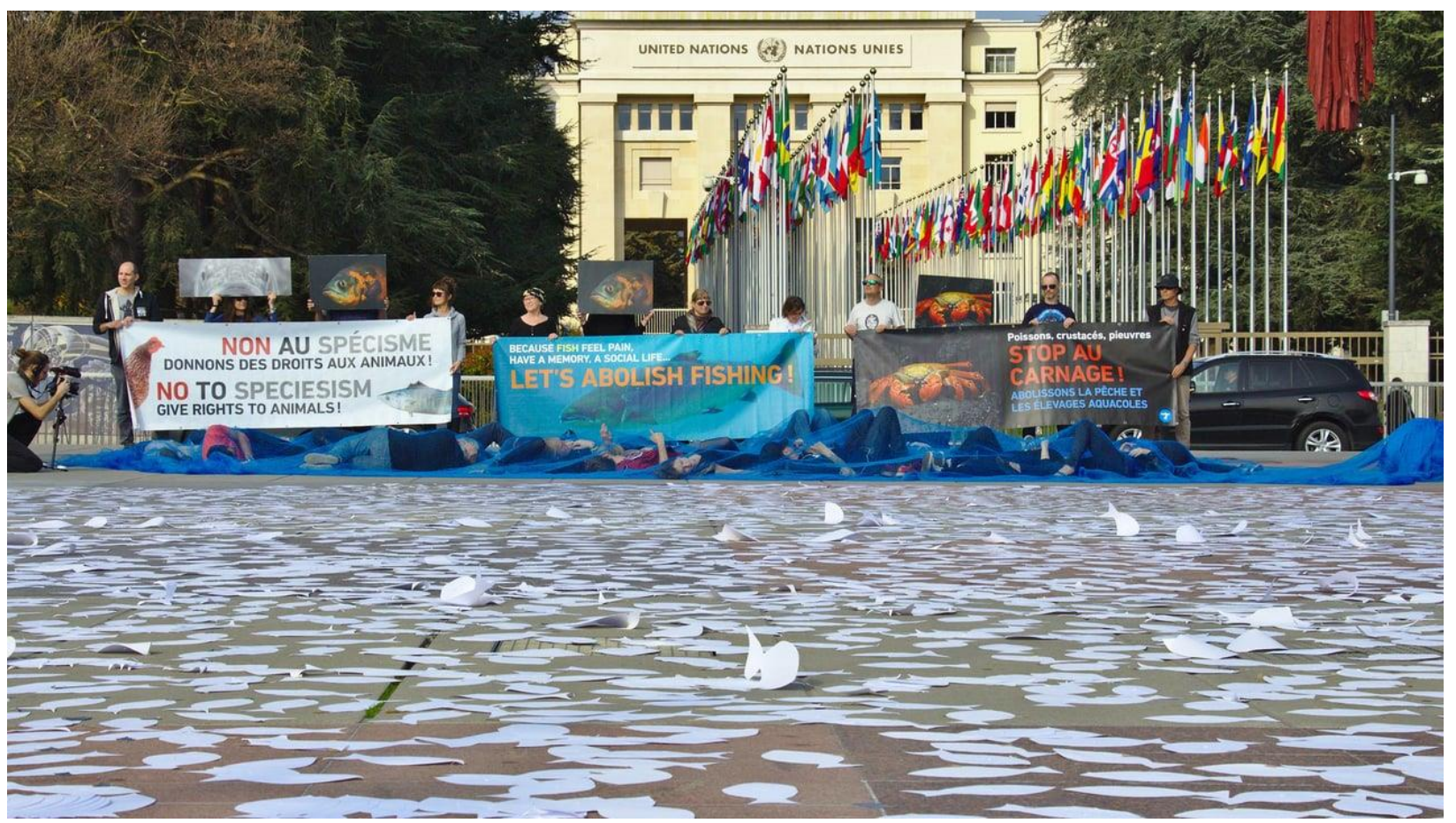

Photo by Association Pour L'Égalité Animale (PEA) at Lournée Mondiale pour la Fin de la Pêche (JMFP) $\underline{24.03 .2018}$

(Reprinted with permission) 


\section{References}

Allen, W. L., Street, S. E., \& Capellini, I. (2017) Fast life history traits promote invasion success in amphibians and reptiles. Ecology Letters 20: 222-230.

Balcombe, J. (2016a) In praise of fishes: Précis of What a fish knows (Balcombe 2016). Animal Sentience 8(1).

Balcombe, J. (2016b) What a Fish Knows: The Inner Lives of Our Underwater Cousins. New York: Farrar, Straus \& Giroux.

Bshary, R. (2006) Machiavellian intelligence in fishes. pp. 277-297 in: Brown, C., Laland, K., Krause, J. Fish Cognition and Behavior. Oxford: Blackwell Publishing.

Chiu, C., Xian, W., Moss, C. F (2009) Adaptive echolocation behavior in bats for the analysis of auditory scenes. Journal of Experimental Biology 212: 1392-1404.

Cooke, S. J., Cowx, I. G. (2004) The role of recreational fisheries in global fish crises. BioScience 54: 857-859.

Hagedorn, M., Heiligenberg, W. (1985) Court and spark: Electric signals in the courtship and mating of gymnotoid fish. Animal Behaviour 33: 254-265.

Kramer, L. B. (2017) What does it feel like to be an electroreceptive fish? Animal Sentience $8(3)$.

Levenda, K. (2017) Sensitizing humans to fish sentience. Animal Sentience 8(6).

Mood, A. (2010) Worse things happen at Sea: The welfare of wild-caught fish. fishcount.org.uk.

Obrist, M. K. (1995) Flexible bat echolocation: the influence of individual, habitat and conspecifics on sonar signal design. Behavioral Ecology and Sociobiology 36: 207-219.

Ripple W. J., Wolf, C., Newsome, T. M., Hoffmann M., Wirsing, A. J., McCauley, D. J. (2017) Extinction risk is most acute for the world's largest and smallest vertebrates.

Proceedings of the National Academy of Science, U S A, 114: 10678-10683.

Siebeck, U. E. (2017) Fish are flexible learners who can discriminate human faces. Animal Sentience 8(5).

Stauffer, J. R., Jr. (2017) The potential for sentience in fishes. Animal Sentience 8(4).

Vail, A. L., Manica, A., Bshary, R. (2013) Referential gestures in fish collaborative hunting. Nature Communications 4: 1765.

Vail, A. L., Manica, A., Bshary, R. (2014) Fish choose appropriately when and with whom to collaborate. Current Biology 24: R791-R793.

Wintner, R. (2016) Reef society and the tyranny of data. Animal Sentience 8(2).

Woodruff, M. L. (2017) Consciousness in teleosts: There is something it feels like to be a fish. Animal Sentience 13(1). 